\title{
Deep Eutectic Solvents in The Synthesis of Polymers
}

\author{
Masoud Mokhtary* \\ Department of Chemistry, Islamic Azad University, Iran
}

Submission: November 19, 2018; Published: January 23, 2019

*Corresponding author: Masoud Mokhtary, Department of Chemistry, Rasht Branch, Islamic Azad University, Iran

\begin{abstract}
Deep Eutectic Solvents (DESs), a subclass of ionic liquids, have emerged as sustainable and green solvents in chemical reactions. In this minireview article, deep eutectic solvents utilization in the polymer synthesis will be discussed briefly.

Keywords: Deep eutectic solvents; Polymer synthesis; Green chemistry

Abbreviations: DES: Deep Eutectic Solvents; HBA: Hydrogen Bond Acceptor; HBD: Hydrogen Bond Donor; PDCs: Poly Diol-Co-Citrates; PAAc: Poly (Acrylic Acid); PMAAc: Poly Methacrylic Acid; APS: Ammonium Persulfate; EM: Eutectic Mixture; FP: Frontal polymerization
\end{abstract}

Introduction

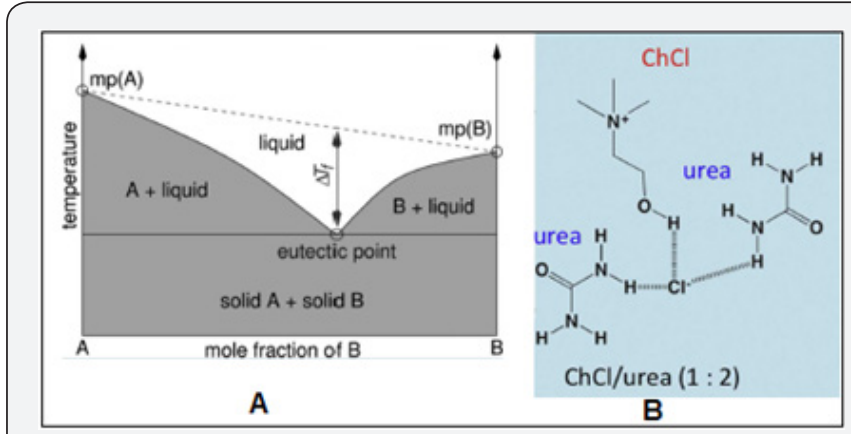

Figure 1: A) Phase diagram of a binary mixture exhibiting a eutectic point,

B) Chemical structure of hydrogen bonding in choline chloride/ urea DES (1:2 molar ratio). Reproduced with permission from Reference [1].

Solvent utilization creates the largest volume of auxiliary waste in polymer synthesis. However, increasing awareness of the environmental problems has led to the use of alternative reaction media to reduce or eliminate organic solvent use. Deep eutectic solvents (DESs) are systems formed from a eutectic mixture of Lewis or Bronsted acids and bases which can contain a variety of anionic and/or cationic species [1]. They incorporate a hydrogen bond acceptor (HBA) and a hydrogen bond donor (HBD), which are able to give a eutectic with a melting point much lower than either of the individual components (Figure 1) [2]. One of the most significant deep eutectic phenomenon's was observed for a mixture of choline chloride and urea in a 1:2 mole ratio respectively. The resulting mixture has a melting point of $12^{\circ} \mathrm{C}$, which makes it liquid at room temperature. DESs are obtained by complexion of quaternary ammonium salts with hydrogen bond donors. The charge delocalization occurring through hydrogen bonding between the halide anion and the hydrogen donor moiety is responsible for the decrease in the freezing point of the mixture relative to the melting points of the individual components (Figure 2) [3].

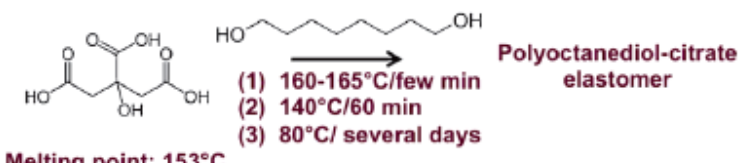

Melting point: $153^{\circ} \mathrm{C}$

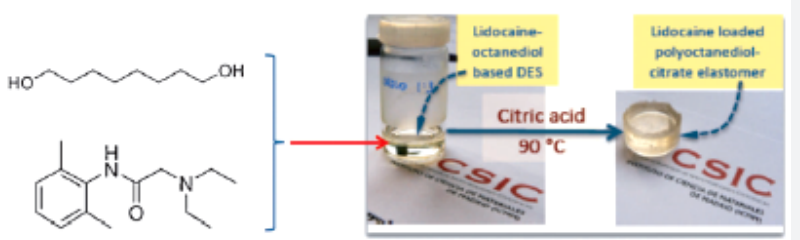

Melting point: $41^{\circ} \mathrm{C}$

Figure 2: Scheme representing the synthesis of poly (octanediol citrate) from

a) 1,8-octanediol dissolved in molten citric acid $\left(\right.$ at $160^{\circ} \mathrm{C}$ ), and b) a eutectic mixture composed of 1,8-octanediol and lidocaine, the low melting point of which allows the dissolution of citric acid and its subsequent polycondensation at temperatures as low as $90^{\circ} \mathrm{C}$. Reproduced with permission from references $[7,8]$.

DESs share many characteristics of conventional ILs (e.g. non-volatile, nonreactive with water, and biodegradable) while it offers certain advantages. The preparation of eutectic mixtures in a pure state can be accomplished more easily than that of ILs with no need of post-synthesis purification due to the purity of the resulting DES will simply depend on the purity of its individual components. Moreover, the low cost of those eutectic mixtures based on readily available components (for instance, urea and choline chloride are a well-known example) makes 
them particularly desirable for large-scale synthetic applications [4].

\section{Green Polycondensations}

The polycondensation of citric acid with 1,8-octanediol for the synthesis of Poly (Diol-Co-Citrates) (PDCs), were first reported by Yang et al. [5,6] in 2004 and, similar to other biocompatible polyesters, have indicated tremendous versatility as polymeric networks for regenerative medicine. The conventional synthetic process first consists of citric acid melting by thermal treatment at $160-165^{\circ} \mathrm{C}$ for a few minutes (Figure 1). Then, 1,8-octanediol is dissolved in this molten phase and polycondensation starts. The temperature is maintained at $140^{\circ} \mathrm{C}$ over $60 \mathrm{~min}$, and then reduced to $80^{\circ} \mathrm{C}$ to let the reaction to proceed over several days until completion. Deep eutectic solvent-assisted syntheses offer an interesting opportunity to fits well with green chemistry. For example, the mixture of 1,8-octanediol and lidocaine, which is a local anesthetic, in stoichiometric molar ratios forms a eutectic with a melting point of about $40^{\circ} \mathrm{C}$. Citric acid can easily be dissolved in this eutectic mixture and polycondense with 1,8-octanediol at temperatures far below those described above for regular polycondensations (Figure 2). Lidocaine was finally entrapped with a high loading due to the stoichiometric in which it formed part of the eutectic mixture into the resulting polyesters. Thus, we were able to obtain drug-eluting materials, the controlled release of which into an aqueous medium was simply based on the biodegradable character of the polyester network. It is worth noting that lidocaine would decompose (at least, partially at $155^{\circ} \mathrm{C}$ ) following regular polycondensation $[7,8]$.

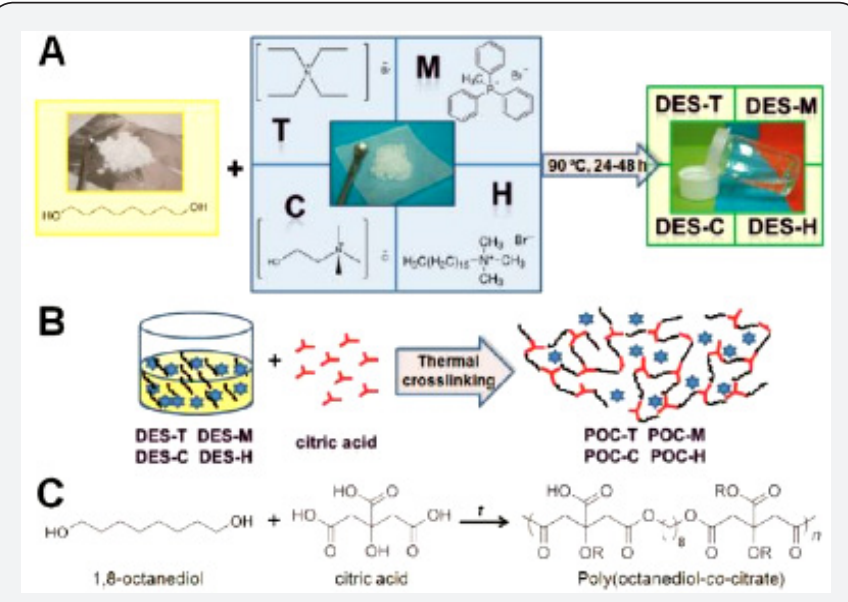

Figure 3: DES-assisted synthesis of poly(octanediol-co-citrate) polyesters.

A) Preparation of the different DESs and physical appearance of the components before and after DES formation.

B) DES-assisted synthesis of POC elastomers containing antibacterial compounds. 1,8-Octanediol molecules are schematized as black curled lines; antibacterial compounds, as blue stars; and citric acid, as red trident figure C) Diagram of the synthesis of standard POC. $t$ is the curing temperature. Reproduced with permission from Reference [9].

Also, Serrano et al. [9] in another research, prepared biodegradable poly(octanediol-co-citrate) polyesters with acquired antibacterial properties by the DES-assisted incorporation of quaternary ammonium and phosphonium salts into the polymer network (Figure 3) [9]. Remarkably, the resulting polymers preserve their cytocompatibility while showing elastic properties advantageous for their use as wound dressings. In the resulting polymers, the presence of salts such as: choline chloride, tetraethylammonium bromide, hexadecyltrimethylammonium bromide, and methyltriphenylphosphonium bromide, inhibits bacterial growth in the early post implantation steps, as tested in cultures of Escherichia coli on solid agar plates.

From DSC scans, the melting points (Tm) for DES-C, DES-T, DES-H, and DES-M were identified at $52,47,54$, and $55^{\circ} \mathrm{C}$, respectively, which were significantly below those of any of its individual components (i.e., $61^{\circ} \mathrm{C}$ for 1,8 -octanediol, $302-305^{\circ} \mathrm{C}$ for compound $\mathrm{C}, 285^{\circ} \mathrm{C}$ for $\mathrm{T}, 248-251^{\circ} \mathrm{C}$ for $\mathrm{H}$, and $230-234^{\circ} \mathrm{C}$ for M) (Figure 4). Hydrogen bonding between the halide anion of quaternary nitrogen or phosphonium salts and the 1,8-octanediol as the hydrogen donor moiety is the most plausible explanation for the stabilization of the different DESs formed, as previously described for other DESs [4,7].

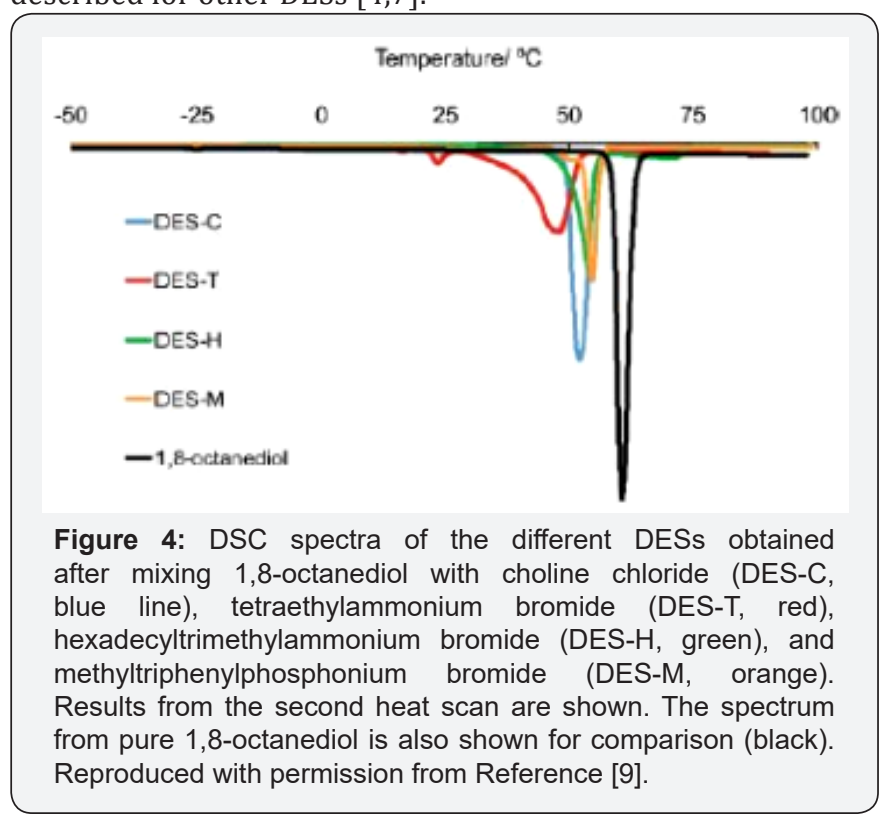

Polymer inhibition of bacterial growth against E. coli was measured as the diameter of the zone of inhibition around polymer discs normalized by the grams of polymer. A clear zone of inhibition was observed around the discs, with values varying from 1.76 (POC-C) to 68.90 (POC-M) mm g-1 of polymer as the minimum and maximum inhibition zones, respectively.

DESs have been used in polycondensations, where one of the components was also a reactant, thus called all-in-one systems [10]. Electrochemical polymerization of conductive monomers has also been explored taking advantage of the ionic conductivity of DESs [11-15], including the $\mathrm{FeCl}_{3}$-catalyzed oxidative polymerization of 3-octylthiophene [14]. Recently, DESs were reported to play the role of curing agents in epoxy resins [16], monomer [17,18] and initiator [19] in ring-opening polymerization. 


\section{Free-radical polymerization of DESs: deep eutectic monomers}

In free-radical polymerization of DESs, monomers able to polymerize undergo free-radical polymerization while taking part in a DES, as hydrogen bond donor or ammonium salt, so called DES monomers [20]. The introduction of DESs in freeradical polymerizations was reported by the synthesis of Poly (Acrylic Acid) (PAAc) and Poly (Methacrylic Acid) (PMAAc) monoliths by frontal polymerization [21]. Frontal polymerization (FP) is normally performed with neat monomers but can be accomplished in solution [22-25]. Bednarz et al. [26], described the free radical copolymerization of itaconic acid-forming DES with $\mathrm{ChCl}$-and AAm by in situ polymerization-crosslinking of the DES (Figure 5). Itaconic acid is a bio-based monomer containing an unsaturated moiety that slowly polymerizes by free radicals; it also has two carboxylic groups available as HBDs [27]. As result of Itaconic Acid (IA) transformation into DES, copolymerization initiated by persulfate proceeded faster and at lower temperature than in water and produced higher crosslinked hydrogels, pointing to a catalytic effect of $\mathrm{ChCl}$. Based on the results of itaconic acid free-radical polymerization initiated by Ammonium Persulfate (APS) in water, it was concluded that DES acted as the solvent of itaconic acid and also as catalyst in free-radical polymerization processes [26]. According to this study, the copolymerization-crosslinking of itaconic acid with $\mathrm{N}, \mathrm{N}$-methylenebisacrylamide in the DES was a useful method for the preparation of hydrogels. Comparative studies indicate that itaconic acid undergoes faster copolymerization in DES than in water, and probably for that reason the obtained product has higher cross-link density [26].

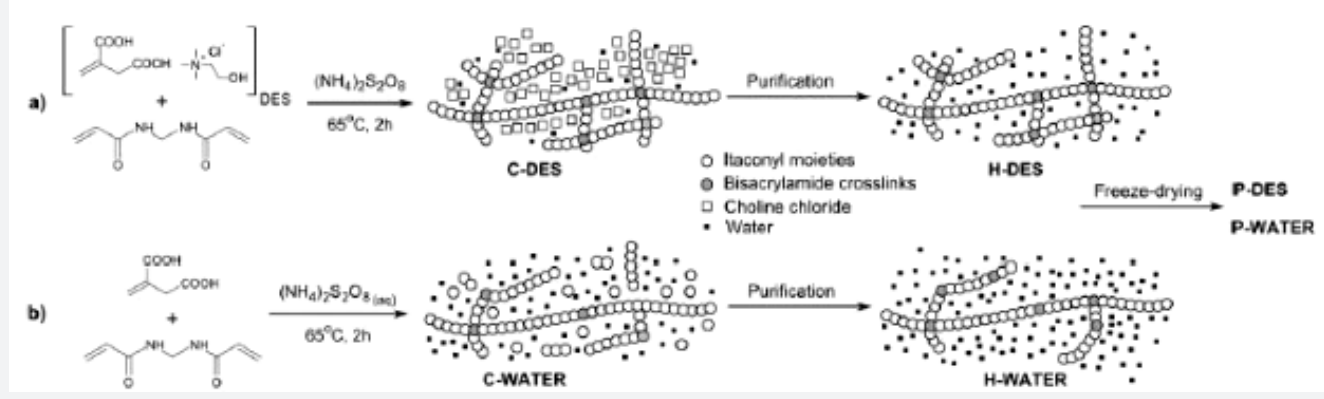

Figure 5: Preparation of poly (itaconic acid) crosslinked by BAA by:

a) polymerization in DES (P-DES) and

b) polymerization in water (P-WATER), and tentative structures of resulting composites (C-DES and C-WATER) and hydrogels (H-DES and H-WATER). Reproduced with permission from Reference [26].

\section{DES assisted atom transfers radical polymerization}

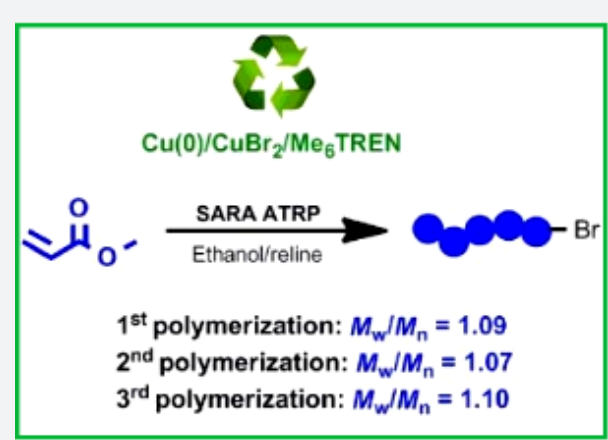

Figure 6: Efficient catalyst recycling in atom transfer radical in polymerization of methyl acrylate. Reproduced with permission from Reference [27].

A green solvent system, composed of a eutectic mixture (EM) and ethanol, was used in the supplemental activator and reducing agent atom transfer radical polymerization (SARA ATRP) of methyl acrylate (MA), yielding well-defined polymethyl acrylate (PMA) chains (Figure 6) [27]. In addition, this eutecticbased system allows a straightforward separation of the entire catalytic system, with possibility of reutilization, which is a much advantageous feature for a possible industrial implementation of the SARA ATRP process [27]. In this study, ethanol/reline (choline chloride: urea) mixtures showed to be excellent solvent for the polymerization, providing well-defined PMA (dispersity, $Đ(\mathrm{Mw} / \mathrm{Mn})<1.2)$ as well as affording the recycling of the entire catalytic system $\mathrm{Cu}(0) / \mathrm{CuBr}_{2} / \mathrm{Me}_{6} \mathrm{TREN}$, which could be reused at least two times in new SARA ATRP experiments.

\section{Conclusion}

Deep eutectic solvents provided a reaction medium, so that polymerizations were ultimately performed in a solventless manner. DESs also provided new precursors that favored more efficient polymerizations by decreasing the energy input required for the reaction to proceed. The use of mild reaction conditions in combination with the compositional versatility of DESs, which allows the selection of low toxic components, is also of interest from the viewpoint of green chemistry due to it opens up the way to the design of eco-friendly synthetic methods. DESassisted polymer syntheses met more green principles than those of conventional ones, so, polymers obtained from greener processes have more opportunities to be feasible for green applications than polymers obtained from less green ones. These encouraging results suggest that DES-assisted polymerizations can help to provide synthetic designs and products with a greener character. 


\section{Acknowledgements}

Financial support by Rasht Branch, Islamic Azad University is gratefully acknowledged.

\section{References}

1. Smith EL, Abbott AP, Ryder KS (2014) Deep eutectic solvents (DESs) and their applications. Chem Reviews 114(21): 11060-11082.

2. Tomé LIN, Baião V, da Silva W, Brett CMA (2018) Deep eutectic solvents for the production and application of new materials. Appl Mater Today 10: 30-50.

3. Abbott AP, Capper G, Davies DL, Rasheed RK, Tambyrajah V (2003) Novel solvent properties of choline chloride/urea mixtures. Chem Commun 1: 70-71.

4. Abbott AP, Boothby D, Capper G, Davies DL, Rasheed RK (2004) Deep eutectic solvents formed between choline chloride and carboxylic acids: versatile alternatives to ionic liquids. J Am Chem Soc 126(29): 9142-9147.

5. Yang J, Webb AR, Ameer GA (2004) Novel citric acid-based biodegradable elastomers for tissue engineering. Adv Mater 16(6): 511-516.

6. Yang J, Webb AR, Pickerill SJ, Hageman G, Ameer GA (2006) Synthesis and evaluation of poly (diol citrate) biodegradable elastomers. Biomaterials 27(9): 1889-1898.

7. Serrano MC, Gutirrrez MC, Ferrer ML, del Monte F (2012) Synthesis of novel lidocaine-releasing poly(diol-co-citrate) elastomers by using deep eutectic solvents. Chem Commun 48: 579-581.

8. Del Monte F, Carriazo D, Serrano M C, Gutiérrez MC, Ferrer ML (2014) Deep Eutectic Solvents in Polymerizations: A Greener Alternative to Conventional Syntheses. Chem Sus Chem 7(4): 999-1009.

9. García Argüelles S, Concepción Serrano M, Gutiérrez MC, Luisa Ferrer M, Yuste L, et al. (2013) Deep eutectic solvent-assisted synthesis of biodegradable polyesters with antibacterial properties. Langmuir 29(30): 9525-9534.

10. Carriazo D, Serrano MC, Gutiérrez MC, Ferrer ML, del Monte F (2012) Deep-eutectic solvents playing multiple roles in the synthesis of polymers and related materials. Chem Soc Rev 41: 4996-5014.

11. Fernandes PMV, Campiñna JM, Pereira CM, Silva F (2012) Electrosyn thesis of polyaniline from choline-based deep eutectic solvents: morphology, stability and electrochromism. J Electrochem Soc 159(9): G97-105.

12. Prathish KP, Carvalho RC, Brett CMA (2014) Highly sensitive poly(3,4-ethylenedioxythiophene) modified electrodes by electropolymerisation in deep eutectic solvents. Electrochem Commun 44: 8-11.

13. Fernandes PMV, Campiǹa JM, Pereira NM, Pereira CM, Silva F (2012) Biodegradable deep-eutectic mixtures as electrolytes for the electrochemical synthesis of conducting polymers. J Appl Electrochem 42(12): 997-1003.
14. Park TJ, Lee SH (2017) Deep eutectic solvent systems for $\mathrm{FeCl}_{3}$-catalyzed oxidative polymerization of 3-octylthiophene. Green Chem 19: 910-913.

15. Hosu O, Bârsan MM, Cristea C, Sandulescu R, Brett CMA (2017) Nanostructured electropolymerized poly (methylene blue) films from deep eutectic solvents: optimization and characterization. Electrochim Acta 232: 285-295.

16. Máka H, Spychaj T, Sikorski W (2014) Deep eutectic ionic liquids as epoxy resin curing agents. Int J Polym Anal Charact 19(8): 682-692.

17. Coulembier O, Lemaur V, Josse T, Minoia A, Cornil J, et al. (2012) Synthesis of poly(L-lactide) and gradient copolymers from a L-lactide/ trimethylene carbonate eutectic melt. Chem Sci 3: 723-726.

18. Pérez-García MG, Gutiérrez M C, Mota-Morales J D, Luna-Bárcenas G, del Monte F (2016) Synthesis of biodegradable macroporous poly(l-lactide)/poly(«-caprolactone) blend using oil-in-eutectic-mixture high-internal-phase emulsions as template. ACS Appl Mater Interfaces 8(26): 16939-16949.

19. García-Argüelles S, García C, Serrano MC, Gutiérrez MC, Ferrer ML, et al. (2015) Near-to-eutectic mixtures as bifunctional catalysts in the low-temperature-ring-opening-polymerization of caprolactone. Green Chem 17: 3632-3643.

20. Mota-Morales JD, Sánchez-Leija RJ, Carranza A, Pojman JA, del Monte F, et al. (2018) Free-radical polymerizations of and in deep eutectic solvents: Green synthesis of functional materials. Prog Polym Sci 78: 139-153.

21. Mota-Morales JD, Gutiérrez MC, Sanchez IC, Luna-Bárcenas G, del Monte F (2011) Frontal polymerizations carried out in deep-eutectic mixtures providing both the monomers and the polymerization medium. Chem Commun 47: 5328-5330.

22. Pojman JA, Curtis G, Ilyashenko VM (1996) Frontal polymerization in solution. J Am Chem Soc 118: 3783-3784.

23. Chen S, Hu T, Tian Y, Chen L, Pojman JA (2007) Facile synthesis of poly (hydroxyethyl acrylate) by frontal free-radical polymerization. J Polym Sci Part a Polym Chem 45(5): 873-881.

24. Nuvoli D, Alzari V, Nuvoli L, Rassu M, Sanna D, et al. (2016) Synthesis and characterization of poly(2-hydroxyethylacrylate)/ $\beta$-cyclodextrin hydrogels obtained by frontal polymerization. Carbohydr Polym 150: 166-171.

25. Nuvoli L, Sanna D, Alzari V, Nuvoli D, Sanna V, et al. (2016) Double responsive copolymer hydrogels prepared by frontal polymerization. J Polym Sci Part a Polym Chem 54(14): 2166-2170.

26. Bednarz S, Fluder M, Galica M, Bogdal D, Maciejaszek I (2014) Synthesis of hydrogels by polymerization of itaconic acid-choline chloride deep eutectic solvent. J Appl Polym Sci 131: 40608-40615.

27. Maximiano P, Mendonc PV, Santos MRE, Costa JRC, Guliashvili T, et al (2017) Eutectic mixtures as a green alternative for efficient catalyst recycling in atom transfer radical polymerizations. J Polym Sci Part a Polym Chem 55(3): 371-381 
This work is licensed under Creative Commons Attribution 4.0 License DOI: 10.19080/AJOP.2019.02.555586

\section{Your next submission with Juniper Publishers} will reach you the below assets

- Quality Editorial service

- Swift Peer Review

- Reprints availability

- E-prints Service

- Manuscript Podcast for convenient understanding

- Global attainment for your research

- Manuscript accessibility in different formats ( Pdf, E-pub, Full Text, Audio)

- Unceasing customer service

Track the below URL for one-step submission https://juniperpublishers.com/online-submission.php 